\title{
EL TRAJE NUEVO DEL EMPERADOR: ENDOGAMIA, NEPOTISMO, CLIENTELISMO, ÍDOLOS Y MITOS EN LA TRASTIENDA DE LA POESÍA ESPAÑOLA CONTEMPORÁNEA
}

The emperor's new clothes: inbreeding, nepotism, cronyism, idols and myths in the backrooms of the contemporary Spanish poetry.

\author{
ANTONIO ORIHUELA \\ antonioorihuela.orihuela@gmail.com
}

RECIBIDO: 28 DE ENERO DE 2018

ACEPTADO: 30 DE ENERO DE 2018

RESUMEN: El presente artículo pone de manifiesto como son aspectos extrapoéticos (mandarinatos, redes clientelares, influencia institucional, control de recursos públicos, circuitos de dones, sobreexposición médiatica, etc.) los que han dado consistencia, visibilidad, hegemonía y poder a determinados discursos poéticos siempre en consonancia con la ideología dominante, desde los años setenta hasta la actualidad. Así mismo, pone de relieve como este mismo entramado cultural, político, mercantil e ideológico al servicio de la desactivación social y la naturalización del capitalismo como vida cotidiana, ha agostado, ninguneado e invisibilizado toda poesía disidente, centrándonos especialmente en el fenómeno de la poesía de la conciencia crítica, que viene denunciando, desde los años noventa, la vida dañada bajo el capitalismo desde postulados radicales y heterodoxos, y prácticas sociales libertarias, colectivistas y autónomas.

PALABRAS CLAVE: Novísimos, poesía de la experiencia, hegemonía, ideología

dominante, capitalismo, poesía de la conciencia crítica

Abstract: The aim of this paper is to analyze some extrapoetic elements (clientelar networks, institutional influence, control of public resources, gift circuits, overexposure, etc.) that have given visibility, hegemony and power to certain poetic discourses always in line with the dominant ideology, from the seventies to the present. Likewise, it highlights how this same cultural, political, commercial and ideological framework at the service of the social deactivation and naturalization of capitalism as everyday life, all dissenting poetry has been exhausted, neglected and made invisible. This paper focuses especially on the phenomenon of "poesía de la conciencia crítica", which has been denouncing, since the nineties, life damaged under capitalism from a radical and heterodox point of view, related to libertarian, collectivist and autonomous social practices.

KEY WORDS: Novísimos, Experience Poetry, Hegemony, Dominant Ideology, Capitalism, "Poesía de la Conciencia Crítica".

Orihuela, Antonio.

"El traje nuevo del emperador: endogamia, nepotismo, clientelismo, ídolos y mitos en la trastienda de la poesía española contemporánea”.

Kamchatka. Revista de análisis cultural 11 (Julio 2018): 17-37

DOI: 10.7203/KAM.11.11423 ISSN: 2340-1869

Monográfico LECTURAS DEL DESIERTO: NUEVAS PROPUESTAS POÉTICAS EN ESPAÑA 
-Señor conde Lucanor -respondió Patronio-, para que veáis lo que, según mi parecer, os conviene más, me gustaría que supierais lo que sucedió a un rey con tres granujas que fueron a estafarle.

Don Juan Manuel. El conde Lucanor

\section{INTRODUCCIÓN ${ }^{1}$}

La poesía está desnuda, siempre lo estuvo, a pesar de su corte de aduladores que nos dicen que solo se engalana con los más absurdos ropajes de su conveniencia. La extensa red de silencios, complicidades y favores que recubren su visibilidad, convertida en producto cultural de las élites, ha hecho imposible la evidencia: la poesía está desnuda y su historia tiene más que ver con la exclusión y el sectarismo, que con el rigor crítico e histórico. Mientras siga en manos de las élites intelectuales, ellas mismas producto de un nepotismo y un clientelismo servil y endogámico, mientras siga disuelta entre los mitos que esa misma élite intelectual sostiene, y mientras siga presa de una investigación crítica perezosa, enrocada en el precedente, la cita y la reproducción de las tesis de los facultados para favorecer la promoción discipular y académica, nunca sabremos qué es lo que ha pasado en nuestras letras. La historia quedará escrita como hasta ahora en función de mandarinatos, redes clientelares muy disciplinadas que tejen auténticas tramas de control e influencia institucional, políticas editoriales y operaciones de promoción de determinados relatos en consonancia con el discurso dominante que, de paso, silencian o barren toda disidencia, toda oposición. Sobre esta contradicción fundamental, la desnudez de la poesía y el exceso de vestuario producido por los que han querido agostarla a su gusto, se ha construido la historia de la poesía española contemporánea.

Juicios que defienden los intereses de la familia o la tendencia, constituyendo una especie de egoísmo gregario que sólo protege sus intereses de grupo; unido, paradójicamente, a un fuerte individualismo y egocentrismo a la hora de juzgar la realidad no como lo que es, sino como a uno le parece que es, en tanto guerra por el significado y el control de la palabra, de cara a establecer un discurso totalitario y hegemónico, y la ignorancia de la ideología como un serio obstáculo para interpretar la realidad en la medida que la ideología construye lo real. Sobre estos pilares se construye hoy la poesía española y se impide el conocimiento liberador, pero los mitos y los ídolos no son obstáculos insalvables, más si, a cambio, lo que proponemos es una solución reactiva a unas prácticas amorales y prepotentes.

\section{DESVISTIENDO A SU MAJESTAD}

En el mundo de las letras se produce, a finales de los años sesenta, una reorientación propugnada por la socialdemocracia que cuajará en una auténtica alianza contra el realismo, hegemónico hasta entonces. Esta actitud antirrealista cuajó, en poesía, en la deslavazada antología

\footnotetext{
${ }^{1}$ Una versión previa de este artículo fue publicada en el libro coordinado por Alberto García-Teresa El verso por asalto. Poesía, desobediencia y construcción antagonista. Ciempozuelos: Tierradenadie Ediciones (2008).
} 
preparada por José Ma . Castellet Nueve Novísimos, hecha por encargo de Carlos Barral en 1970.

El volumen, aunque apenas tuvo repercusión entre los escasos lectores de entonces, abrió el camino para esta operación de liquidación de los fundamentos discursivos del realismo en poesía. El mismo Castellet lo confesaba en una entrevista allá por el 2001:

\footnotetext{
Literariamente el franquismo se había acabado... se había acabado aquello de la poesía como arma de combate... se trataba de hacer un juego con novísimos y nueve. Podían haber sido ocho o diez o doce, pero nueve sonaba mejor... Había un cansancio generacional. Empezaban a resultar los planes de desarrollo de Franco y los nuevos escritores eran cultos, ricos, altos, guapos, muy leídos y habían viajado al extranjero con el dinero que sus papás habían ganado con Franco.
}

En realidad, el título lo había copiado Castellet de una antología italiana I Novissimi, que a mediados de los sesenta se había publicado con mucho éxito y había dado lugar incluso a que la crítica de allí hablara de una nueva generación poética. En la misma editorial que salieron los novísimos italianos, Einaudi, saldría, en 1976, una versión de los novísimos de Castellet, aunque reducida a cuatro, lo que da idea de la calidad del proyecto original. En efecto, Nueve Novísimos no tiene ni pies ni cabeza, no hay ningún nexo de unión entre los antologados más allá de la amistad con Castellet o con Gimferrer, que anduvo también metiendo baza en la confección de la misma, pues unos son poetas, otros son narradores, y los estilos, más que divergentes, son antagónicos.

Para los defensores del realismo, la antología no era sino poesía de pasatiempo, gélida, frívola, cosas de niños ricos, juglaría de señoritos que quieren sustituir la berza por el sándalo, dirá José Hierro en 1972. Desde el periódico Arriba, tacharán a los nueve novísimos de comunistas y trotskistas, de "agentes de la cocacolonización"; y al libro, de estar al servicio de los intereses económicos de un nuevo imperialismo.

Es claro que la antología de Castellet presentaba un imaginario apenas al alcance de una pequeña élite económica y cultural que poseía los referentes que allí se exhibían o bien que estaba en condiciones de aceptar la propuesta del distanciamiento de una realidad que la mayoría de la población llevaba pegada a la piel. Treinta años después será celebrada y aplaudida por la prensa socialdemócrata: un fenómeno inolvidable, la llama EL PAÍS (24/02/2001) y en parecidos términos se pronuncia EL MUNDO. En 2011 se volvió a reeditar, en plena crisis económica, en medio de la explosión de los realismos críticos, un contexto en el que solo pudo ser considerada como un objeto arqueológico: su tiempo ya había pasado.

Pocas veces se ha hablado tanto de un libro tan poco leído y que apenas supuso un paréntesis en la aún vigorosa producción de poesía social de los años setenta, pero también es cierto que desde los años sesenta, otros poetas, animados por nuevas búsquedas que discurren por caminos diversos, irán agostando el realismo, perdiendo protagonismo en las letras españolas hasta quedar como un fenómeno absolutamente residual hacia finales de los años ochenta, tiempo en el que las corrientes antirrealistas han ido recabando cada vez más adhesiones entre críticos y poetas.

Lo que no deja de resultar curioso es que sea justo a finales de los años sesenta (con el 
mayo francés, huelgas en España, aumento de la represión franquista, proceso de Burgos, etc.), cuando parecía que las posibilidades de subvertir la realidad se tornaban más factibles, cuando muchos escritores decidieran abandonarla, porque, según ellos, los tiempos habían cambiado y las condiciones del país, jen 1970!, eran ya otras, distintas a las de la postguerra, como afirma Goytisolo; o sencillamente, porque el mundo exterior se había convertido en una pesadilla, como subraya Castellet, un ordinario mundo de berzas frente al que la izquierda divina propugnaba la vuelta al lenguaje emancipado de toda dependencia respecto a la realidad y condición fundamental de la autonomía del arte. Esta postura la defenderán desde Gimferrer a Bousoño, pasando por Jenaro Talens, Carnero, Azúa o Leopoldo María Panero, mientras otros, como Vázquez Montalbán, reflexionan en esos mismos años sobre su reconsideración como instrumento inútil para el cambio social. En 1981, Juan Benet va más allá y habla de cómo toda la producción artística y cultural española, en su empeño de lucha contra el poder establecido, ha dado lugar a obras muy mediocres, lastrada de elementos bastardos, sin refinamiento alguno, e incluye en ellas la novela realista, la poesía social y la canción protesta.

Ellos serán, durante los años setenta y, sobre todo, los ochenta, los artífices de una escritura que jamás en España concilió tanta voluntad de estilo, belleza y experimentación lingüística; si bien también es cierto que nunca se escribió tanto para decir tan pocas cosas. Pero lo peor es que, con el aplastamiento del realismo, la realidad española de los años setenta y ochenta entró en un estado de semiclandestinidad literaria que hace que hoy, al menos desde la poesía, sea casi imposible registrarla.

A favor, debemos decir que más allá de propugnar la oscuridad, la riqueza de léxico y el ponérselo difícil a los lectores, los novísimos, fundamentalmente los más jóvenes, eran muy buenos lectores, tenían una más que aceptable formación, habían viajado, sabían idiomas (francés, inglés) y estaban imbuidos de referentes culturales ajenos a la tradición patria que suelen citar en sus lenguas vernáculas a menudo. También conocían de primera mano, sobre todo en los casos de Manuel Vázquez Montalbán y Leopoldo María Panero, el mayo francés y la literatura beat, e introdujeron por primera vez en la literatura española nombres de pintores, músicos, cineastas, héroes del cómic o escritores que jamás había sido citados por los poetas de las generaciones precedentes: Anglada Camarasa, Warhol, Tamerlán, Charlie Parker, Bogart, Ava Gardner, Vivien Leigh, Apollinaire, Oliverio Girondo, Pound, Eliot, Constantino Cavafis, Saint-John Perse, Wallace Stevens, los surrealistas franceses o Batman. La aplicación de las técnicas de collage surrealistas, las referencias a los mitos del cine de Hollywood, de los tebeos o del jazz y del pop hicieron que muchos jóvenes decidieran continuar por ese camino de experimentación y que otros, incluso desde la aversión por la estética novísima, reconozcan hoy una deuda de honor con quienes primero se adentraron en esta vía de la reutilización de materiales aparentemente no poéticos.

Muchos los tacharon de culturalistas, esteticistas, decadentes, herméticos o venecianos y los calificativos encajan en ellos, quizás salvo los ya indicados Montalbán y Panero, pero de lo que no cabe la menor duda es de que se trata de una antología que se adelanta no a su tiempo, pero sí a la consolidación de una clase media alta con suficiente poder adquisitivo como para poder participar del mismo capital simbólico que ya manejaban estos poetas extraídos, en su mayor parte, de la burguesía catalana. A partir de mediados de los años ochenta nuestra clase media se 
incorpora a los europeos que hacen turismo. Será entonces cuando los poemas a Venecia crecerán en la poesía española como lánguidos champiñones.

En efecto, por más que uno busque en la poesía que se acepta como canon de los años ochenta, nada encontrará sobre las dictaduras argentinas o chilenas, la caída del muro, el fin de la URSS, el golpe del 23-F, la oposición a la OTAN, las huelgas generales contra el PSOE y su política antiobrera, la conflictividad laboral en el sector industrial, etc. La poesía de esos años perfila un mundo armónico y estable, con el poeta sacudido, en todo caso, por los conflictos sentimentales. Es el mundo de lo privado, expresado en un tiempo feliz, catatónico y ahistórico, lo que los críticos saludan como la máxima libertad a la que puede aspirar un poeta. Quedan atrás, arrumbados, los ideales colectivos de transformación social que los nuevos poetas consideran, cuando menos, despreciables, dignos de ser olvidados en pos de esta nueva etapa centrada en el narcisismo, el sentimentalismo ensimismado y la mercantilización de la vida social en un mundo feliz que se proclama como el mejor de los posibles.

Es un hecho que, a pesar de las consignas dadas tanto por el mercado como por las políticas culturales institucionales, la llamada "poesía social" no desapareció en los años setenta. Al contrario, lo que ocurrirá en esos años es que se produce una explosión de la realidad tardofranquista que hace que la "poesía social", hasta entonces previsible y constreñida, se anude a una multitud de luchas que poco o nada tienen ya que ver con una estrategia clásica de conquista del poder, se hace ingobernable y deja de responder a las viejas consignas del Partido (PCE), se emancipa de cualquier tutela, explora aspectos de la realidad antes no contemplados, y se descubre libertaria, beatnik, hippie, punk, gay, feminista, okupa, ecologista, pacifista, trans... en definitiva: underground; y se expande en tal delirio de libertad, y lo hace con tal vitalidad, que será la nueva socialdemocracia ya instalada en el poder la que tenga que pararle los pies para evitar que salga de las cloacas a donde había bajado y desde donde estaba creciendo con una fuerza y un vigor inusitado gracias al fanzine. A esta explosión de la creatividad descentrada y de signo autónomo, responderá entonces el Estado, por una parte con la violencia propia de sus aparatos represivos y por otra, subvencionando, con una intensidad antes desconocida, toda aquella manifestación cultural dispuesta a plegarse a sus exigencias. Así, en los ochenta, a la par que se liquida esta creatividad de signo autónomo, radical, independiente y alternativa, se institucionaliza el fenómeno de la llamada movida como efecto visible del control estatista que sobre la producción cultural en su conjunto imprimirán las políticas socialdemócratas.

Son tiempos de crisis y frente a ellos la cultura oficial se refuerza subvencionando productos blandos, predigeridos, que celebran, cuando no sencillamente ignoran, la brutal realidad de la sociedad española de los años ochenta. Es el triunfo de la tecnocracia, el pelotazo, la lógica del pisotón, el éxito y el beneficio. Entramos en Europa y entramos también en el tiempo del precariado, de la fragmentación de los sujetos, del individualismo exacerbado, la egolatría, la indiferencia, cuando no la aversión mutua, la descomposición deliberada de los vínculos humanos y el desinterés por lo público... Más allá de los artefactos culturales del momento, entre ellos la poesía culturalista, lo que esta venía a certificar era el fin de una época y el triunfo del yo individuo sobre un nosotros colectivo, del repliegue hacia lo privado y el abandono de la plaza pública, del consumismo desenfrenado frente a la sobriedad militante, del reino del objeto y el desinterés por el sujeto, de la estética frente a la ética, de la apariencia, el 
desencanto y la desideologización frente a los grandes ideales humanistas; y si tuvo resonancia, era porque encajaba como un guante dentro del proyecto cultural que el socialismo quería abanderar como reflejo de su idea de cambio en la sociedad española.

La política cultural socialista se encaminó a construir un imaginario colectivo que, aunque continuaba hablando de convivencia, consenso, etc., ahora estaba cimentado sobre la idea de que éramos un país joven, moderno, vanguardista y desinhibido, aunque en la calle la crisis económica, las reconversiones industriales, el paro y la falta de expectativas para los jóvenes fuera el horizonte real de los españoles de clase obrera.

Esta fue la aportación de las izquierdas al régimen transicional. Su cuota de sangre para poder participar en él se cifró en la desactivación de sus dos únicas bazas: la movilización social y la cultura. La cultura no sólo queda desproblematizada, sino que adquiere, precisamente, ese rol. Crea cohesión, da razón al Estado y elimina problemáticas. Hasta el punto de que la cohesión social en España no está sustentada en la economía o los derechos, sino en la cultura, o mejor dicho en la construcción de una industria cultural encadenada a unos medios de comunicación masivos que siguen siendo el orgullo de gran parte de la clase política. Es decir, en propaganda, pues los productos (libros de poesía, novelas, artículos, canciones, programas, películas, exposiciones, etc.), para ser reconocidos como culturales necesitan ajustarse a lo que la cultura transicional fijó como productos culturales, es decir, los que crean cohesión social y estabilidad política, huyen del conflicto, no problematizan la realidad o bien la solucionan y se manejan en códigos sentimentales. Estos productos culturales son, al día de hoy, el único cemento que cohesiona la sociedad española, la base de nuestra democracia de mercado; de ahí la importancia de que todo se mantenga como hasta ahora.

La cultura, que hasta los años setenta había sido el único patrimonio de la izquierda, fue entregada al Estado y al mercado capitalista prisionera y cautiva. Algunos se resistieron, pero a qué precio. En 1984, el escritor y poeta Julio Vélez señala al emperador para decirle que iba desnudo. Lo hace en un magnífico libro: La poesía española según EL PAÍS (1978-1983). Vélez demuestra con datos lo que todo el mundo sabía, lo que todo el mundo sigue sabiendo hoy: que la práctica totalidad de las reseñas literarias que se publicaban en el suplemento cultural (Arte y Pensamiento, luego Libros, y ahora Babelia) de dicho medio respondía a los intereses editoriales del grupo PRISA, accionista mayoritario de EL PAIS. Julio Vélez ilustró con datos cómo eran los intereses empresariales los que marcaban tendencias así como que los libros de poesía que se reseñaban eran consecuencia de la afinidad de los autores con el crítico, el reseñista o la redacción. Así, Vélez explica cómo son cuestiones ideológicas, clientelares o sencillamente económicas, las que marcan la difusión de un libro, las que logran que una tendencia devenga en hegemónica por simple sobreexposición mediática frente a otras corrientes que se invisibilizan; y que, desde luego, todo esto no tenía nada que ver con el valor literario ni con las palabras mágicas siempre invocadas a la hora de justificar la presencia de un libro de poesía en el papel cuché de los suplementos culturales: la calidad, la originalidad, la genialidad, etc.

Sobre La poesía española según EL PAÍS (1978-1983) se tejió un silencio tan espeso como cómplice. Ni la Asociación de Críticos, ni instancia universitaria alguna, Asociación Colegiada de Escritores o Real Academia... nadie lo rebatió, tal vez porque nada había que rebatir, así que lo 
único que se podía hacer con él era condenarlo al mutismo cómplice, como si nunca hubiera sido escrito, como si lo que denunciaba no necesitara enmienda y reparación si de verdad la crítica literaria tenía aprecio a su trabajo. Julio Vélez señaló la desnudez del emperador, y el emperador, como no era el del cuento, sino el emperador del campo simbólico, lejos de recompensarlo, lo convirtió en un escritor marginal, hoy tan olvidado que apenas queda de su memoria el cariño de los que siguen su estela de rebeldía y disidencia en el CSO que lleva su nombre en Morón de la Frontera. Julio Vélez pagó su osadía al denunciar el silencio cómplice de los diferentes actores implicados en el negocio editorial. Su trabajo, lejos de concitar adhesiones entusiastas, provocó que todo el mundillo literario se alejara de él. A partir de entonces no solo EL PAÍS, sino el resto de los medios se le volvieron esquivos, incluso encontrar hoy en día su libro es una tarea imposible; descatalogado, agotado y puesto fuera de circulación, permanece instalado en un olvido interesado. Ninguna editorial ha sentido hasta el momento la tentación de reeditarlo; ellas sabrán, nosotros sabemos por qué.

Para 1986, el proceso de desactivación está más que completado, ya no hay más cultura que la que crea cohesión social y/o está al servicio del ocio y mercado. El consenso político se apropia de la cultura demandando de ella la construcción de un imaginario de clase media, de donde han desaparecido las contradicciones de clase, las relaciones de explotación y los efectos de la precariedad, la pobreza o la marginalidad; y por consiguiente, quien problematice la vida, critique, combata o intente desmontar lo existente será expulsado de la cultura, en tanto no responde a los parámetros que el Estado ha establecido sobre lo que va a ser cultura. Lo que sí se ajuste a este programa político se llamará cultura, pero ya solo será propaganda del mismo régimen que la cultura debe alimentar para seguir siendo cultura. Es el triunfo de lo aséptico, lo predecible, lo simplón en un ambiente de feliz europeísmo democrático que lo inunda todo. La expo del 92, a pesar del disparate y el despilfarro que supuso, se cerrará entre aplausos. Apenas suscitó disenso y el que motivó fue convenientemente silenciado, balas de la policía incluidas. La cultura aprendió a poner el cazo por escribir y componer al dictado de lo que el poder esperaba de ella, a servir a su orden, a la cohesión y la estabilidad social, y a naturalizar el capitalismo y el mercantilismo como vida cotidiana pero, sobre todo, dejó de hacer preguntas y de pretender llegar a alguna parte. Quienes se resistieron fueron deslegitimados, desarticulados, marginados o criminalizados según el grado de conflictividad que fueran capaces de exhibir y la incidencia social que fueran capaces de alcanzar.

En este panorama desabrido, será al calor de la campaña contra la OTAN y del auge del movimiento antibelicista de mediados de los años ochenta cuando la poesía intentará de nuevo, y desde la izquierda, acompañar este nuevo ciclo de luchas. La operación trataba de repetir la vieja y exitosa alianza antifranquista, pero actualizada. A partir de los presupuestos teóricos de Juan Carlos Rodríguez, que denunciaba a la poesía como un útil ideológico, y del descubrimiento de que la ideología burguesa produce nuestra propia vida, nuestra subjetividad, con la que, en tanto marxistas, había que romper para construir una subjetividad antagónica, una sentimentalidad otra, varios poetas dieron lugar a una reactivación de la vieja "poesía social" reconvertida bajo el marbete de La Otra Sentimentalidad. Pero su programa, con el tiempo, se irá diluyendo hasta terminar reducido a la confirmación del imaginario de la socialdemocracia y la libre empresa, basculando entre el malditismo (o el exilio espiritual, según caracteres poéticos) de baja 
intensidad, protagonizado por los poetas de la pequeña burguesía decadente, y el hedonismo de la cultura del dúplex propio de los poetas de las clases medias ascendentes. Lo colectivo fue cediendo paso al círculo de lo próximo conocido, es decir, al propio campo cultural y profesional, y después fue confundiendo el imaginario privado del poeta con el de cualquiera. Abandonada la lógica materialista de la lucha de clases, estos poetas concluirán que escriben poesía para personas normales. Pues eso. Había nacido la poesía de la experiencia.

El mercado, como ya había demostrado Julio Vélez, controla el mundo de los libros y lo que se debe escribir en ellos. Y para servir al mercado, se empiezan a organizar los líderes de la norma y los grupos, aglutinados en torno al control de premios, publicaciones, críticas y subvenciones. Frente a un Javier Egea que pondrá fin a sus días clamando "¡Me quedo solo pero no me vendo!", en los siguientes veinte años, los poetas de la experiencia irán copando el campo literario a la zaga del irresistible ascenso de Luis García Montero, convertido en jefe de filas indiscutible tras conquistar

unas cuotas de popularidad, protagonismo y poder nunca vistos en un hombre de letras (ediciones críticas de los grandes, participación como jurado en una inabarcable cantidad de premios de poesía, presencia decisoria en el mundo editorial, capacidad de opinión y acceso a los medios más prestigiosos, omnipresencia mediática, comisariado de grandes efemérides culturales generosamente subvencionadas... (Granados, 2011).

En la cuneta quedaron otras corrientes que, a pesar de presentar también en sociedad sus propios manifiestos, incluso en la misma Granada!, y organizar también salones, congresos, cursos de verano, controlar asociaciones de críticos, premios, suplementos culturales, antologías y editoriales terminaron siendo barridas por los poetas de la experiencia. Así se expresaban en el "Manifiesto de Granada", los poetas de la Diferencia, clamando doloridos su pérdida de influencia y criticando a los poetas de la experiencia unos comportamientos que a ellos mismos tampoco les eran ajenos:

\footnotetext{
Premios amañados, cenáculos auspiciados por el poder, consignas de dudosos jefes literarios, patentes de corso para impartir prestigio, críticos sectarios... Denunciamos especialmente el estado de arbitrariedad de los poderes públicos en orden a subvenciones que provocan el tráfico de influencias en manos de particulares. (...) Los cuales se sirven de los impuestos de los ciudadanos para imponer sus intereses, aplastando y condenando al silencio a los que representan diferentes alternativas (Bellveser, 2016:150).
}

Sí, estaban en lo cierto al denunciar la corrupción dentro del campo poético, pero esta no era más que reflejo de la degeneración de la vida pública española y de unas instituciones culturales que no fueron tan generosas con ellos en aras a su reconocimiento y visibilidad como con los poetas de la experiencia.

Se equivocaban los poetas de la Diferencia cuando la principal acusación que hacían de los poetas de la experiencia era llamarlos "los poetas del régimen"; en realidad todos eran poetas del régimen; todos querían emocionar con su poesía, impregnarla de lo sensible, lo íntimo, lo bello, los buenos sentimientos, en suma, de lo poético, que no es más que la última habitación alquilada por el insconsciente pequeñoburgués. Con la diferencia de que, frente a su poesía trascendentalista, los que ostentaban el poder en las instituciones -indistintamente de que fueran del PP o el PSOE- estaban más cerca del relato realista, urbano y pequeñoburgués, -que concitó 
la admiración del propio Aznar como declarado lector de García Montero-, pues era, al fin y al cabo, la poesía que hablaba de ellos, de "las personas normales", las que cogen taxis, pasan por los arcos de seguridad de un aeropuerto y dan pregones en el Corpus.

El que durante más de treinta años nos hayan hecho creer que éramos ricos, guapos y europeos no ha conseguido sino empeorarlo todo aún más. Nuestro modelo político, teñido de fascismo sociológico, acabó con la discrepancia y la crítica y puso cerco a la libertad de expresión. El consenso político se había apropiado de lo social y la construcción de un imaginario de clase media había hecho desaparecer las contradicciones de clase, las relaciones de explotación y los efectos de la precariedad, la pobreza o la marginalidad. Pasada la resaca de los bares y los amores de alborada, la poesía de la experiencia derivó al formato en el que continúa hoy día, como una poesía realista meditativa, intimista, de ritmo contenido, enrocada en la reflexión sobre un yo subjetivo pero verosímil, desencantado, escéptico, desengañado de las utopías, los ideales y los sueños suculentos de la izquierda y, sobre todo, empeñada en confundir la particular vida del poeta pequeño burgués y su realidad de clase media alta con la vida y la realidad en su conjunto, o al menos esa es su ilusión; pensar que sus ilusiones y desilusiones de clase son en realidad ilusiones y desilusiones colectivas.

A la vez que las relaciones de dominación, control y reproducción hegemónica se consolidan, los postulados teóricos de la otra sentimentalidad devenida experiencia se van relajando tanto, que para finales de los años noventa, el poeta ya sólo está comprometido con su obra, con el placer; en suma, con la poesía (lo mismo que antes los poetas venecianos sólo habían estado comprometidos con Venecia); y la revolución está en descubrir nuevas posibilidades expresivas. Si no fuera por la persistencia del lenguaje realista, podríamos decir que la poesía de la experiencia prácticamente concluía en las prácticas que había denunciado entre los novísimos o los poetas de la diferencia: idealismo y narcicismo se daban la mano también en ellos para producir un relato conservador, cuando no sencillamente reaccionario, reflejo de una clase media aburguesada, que mira con resignada aceptación y conformidad acrítica un mundo que, aunque no les gusta, es, en definitiva, el único que les asegura su estatus.

Instalados en esta identidad poemática, los viejos poetas de la experiencia reculan hacia el lenguaje como patria del poeta. Desconfiados de una realidad que ellos mismos han contribuido a pudrir, tienen claro que su mejor estrategia está en la palabra poética, allí donde hecha poema resistirán intactos todos los sueños. Llamadas al festín algunas de las viejas glorias recicladas de la poesía social (véase Ángel González), éstas entonan su mea culpa y consideran que superado el franquismo, este nuestro tiempo histórico es ya un periodo normal en el que se puede vivir al margen de la Historia, enclaustrarse en un mundo privado sin indignidad, el lugar donde escribir poemas que así no habrán perdido ni un ápice de la libertad creativa y las opciones estéticas a las que hubo que renunciar en la dictadura (González, 2003:63).

Los alumnos, becarios, discípulos y familiares poéticos de los poetas de la experiencia, que directamente ya nacieron bajo los efectos del éter de la socialdemocracia y no tenían que justificar juveniles veleidades marxistonas, asumieron de sus próceres con total naturalidad que el compromiso es más bien cosa del ciudadano y no del poeta, aunque no explican cómo se puede ser poeta sin ser ciudadano. También considerarán que hay otros cauces más apropiados que la 
poesía para expresar las convicciones personales o los conflictos sociales. Así, lo que nació como programa revolucionario se afirma hoy desde los suplementos de papel cuché como forma íntima de rebeldía interior. Estamos ante la sedición de los ensimismados, los que entienden que nada les atañe, apela, reclama y pide su posicionamiento a menos que desde las instancias políticas $\mathrm{y} / \mathrm{o}$ mediáticas a las que sirven así se les indique.

La postmodernidad llega así también a configurar su poética, la que renuncia al nosotros, a problematizar la dimensión biopolítica de la realidad. Se hablará de la irrupción de una poesía deshabitada, del fragmento, de la incertidumbre, de la joven experiencia, pero detrás de ella, a poco que se rasque, lo que encontramos es fijación del individuo al orden social dominante, es decir, producción de ideología capitalista en estado puro.

Estamos ante la continuidad de la poesía de la experiencia, que ahora acentúa sus rasgos meditativos e intimistas por otros medios, bien a través de una poesía de seres y formas huecas, construida sobre la insuficiencia, la angustia, la desorientación, la carencia, el derrumbamiento y el sinsentido del mundo; bien a través de una percepción que interpreta el mundo de forma fracturada, inconexa, discontinua, desgajada y desapegada de los demás, de su entorno y de las relaciones entre uno y otro como efecto de un individualismo grosero y amnésico.

Los recién llegados continuarán repitiendo los mismos esquemas, hablando de la necesidad de regeneración ética y reincidiendo en las mismas redes de producción, difusión y consumo endogámicas, intercambiándose premios, congresos, ediciones, reseñas y publicaciones, y a la vez, quejándose de que son los otros los que hacen estas cosas (Abril, 2016:359). Pocas confesiones tan rotundas y certeras como la del "arrepentido" Antonio Cienfuegos, ex miembro del "Círculo de Poesía" del virrey mexicano Alí Calderon cuando afirma:

le escuché muchas veces a Ali: "La poesía, mi Toño, no tiene nada de poesía, todo es política, todo es saber hacer política. Poemitas cualquiera puede escribir". Esto era muy cierto, ninguno de ellos escribe buena poesia, sin embargo bicieron un entramado de corrupción en donde envolvieron a gente muy poderosa y con mucho peso literario en México (...) y en el extranjero: Waldo Leyva (Cuba), Omar Lara (Chile), Jorge Galán y Roxana Méndez. (El Salvador), Luís García Montero, Jesús García Sánchez. (Chus Visor), Raquel Lanseros, Daniel Rodríguez. Moya, Benjamin Prado y Fernando Valverde (España), Federico Díaz Granados, Ramón Cote y Andrea Cote (Colombia), Xavier Oquendo (Ecuador), Carlos J. Aldazábal y Ana Wajszczuk (Argentina), entre otros. Prácticamente todos los que aparecen en la antología "Poesía ante la incertidumbre" editada por Visor en 2011, están relacionados, coludidos y en contubernio para otorgarse premios, becas e invitarse a festivales a lo largo de toda Iberoamérica (Cienfuegos, 2013).

Entre un extremo y otro, con la originalidad que surge ajena al mundo académico, podríamos situar la poesía de la joven experiencia, un fenómeno ligado a la llegada a las redes sociales de los primeros adolescentes nativos digitales, que la consumen de forma masiva para sorpresa de las élites intelectuales que pensaban que el cortijo de lo poético era suyo y creían que vender muchos libros era agotar una edición de trescientos ejemplares. Y lo mejor de todo es que si, por un lado, han dinamitado las degradantes relaciones discípulo/maestro necesarias para que se les hiciera un hueco a los jóvenes en cualquier parnasillo universitario o de provincias, por otro, han hecho saltar por los aires las relaciones simbióticas que se daban entre autores, editores, críticos, libreros y consumidores como forma de asegurarse su supervivencia. El poeta más famoso de España ya no es el que vende tres mil ejemplares de un libro, sino un joven cantautor 
desconocido o una adolescente, estudiante de bachillerato, que venden sesenta mil libros sin pasar por ninguna piedra ni tener que haberse tragado unos cuantos sapos.

Cuando todos certificábamos que la poesía carecía de interés para el mercado y solo funcionaba, como hasta ahora, como un bien simbólico o venal (lo que explicaba lo encarnizado de las batallas que se han desarrollado dentro de ella y lo difícil que era establecer un criterio claro de qué era bueno en poesía porque, sencillamente, no ha habido ni público ni consumidores para juzgarla más allá del nepotismo crítico de la élite cultural), llega esta primera generación de nativos digitales a la adolescencia, ese periodo que se extiende hoy como hecho administrativo hasta los treinta y cinco años, y se produce una explosión de blog y cuentas de Twitter, Instagram, MySpace o Youtube en donde van dejando sus comentarios, videos, etc.; y empiezan a aglutinar seguidores por cientos de miles y millones..., al punto de que hoy son los grandes grupos editoriales los que andan a la caza de estos fenómenos de masas, rastreando sus perfiles, sus seguidores y ofreciéndoles producirles lo que quieran: discos, libros de poesía o botijos, que al capital tanto le da.

Pero no hay que dejarse arrastrar por el entusiasmo, esta poesía mainstream de la joven experiencia es, como todo lo que baja desde la ideología dominante, tan estandarizada como previsible, basada en los valores de las clases hegemónicas. Estamos, pues, ante la comercialización no solo de un producto, en este caso un libro de poesía para un público adolescente, sino ante la exposición de un estilo de vida, y en el peor de los casos ante la planificación de una forma de estar en el mundo y la comercialización de una emoción saturada de efusión sentimental, en una horquilla que va desde la cursilería, pasando por el engreimiento, hasta llegar a un erotismo no exento de tintes machistas...

La poesía joven que se está vendiendo a paladas no puede ser sino el reflejo del joven que ha construido la ideología conservadora, el refugio intimista en el que el sujeto reelabora su personalidad y, por tanto, tiene que ser individualista e incapaz de albergar algún sueño colectivo, desengañada de todo, pesimista, girando siempre en torno al amor y el desamor, temas, la mayor parte de las veces, expresados desde posicionamientos reaccionarios, patriarcales y ultraliberales. No es casual que en plena efervescencia del 15M, con los jóvenes indignados en la calle, con los chavales de los institutos en pie de guerra en Valencia, en Madrid, en toda España..., de pronto surja un fenómeno tan extraño como el de esta poesía, promocionada por editoriales profundamente reaccionarias que si buscan algo un poco más allá del mero lucro, es ponerse al servicio de la neutralización del pujante y reivindicativo movimiento estudiantil, proyectando sobre él una sociabilidad de corte autista, individualista, ególatra, cuyo único objetivo es reconfigurar personalidades reforzando su alienación en la soledad de sus habitaciones, reconstruyendo incesantemente su personalidad en las redes sociales, aislados, empachados de desamor y literatura artúrica.

Lo absurdo sería pensar que la poesía de la experiencia, en tanto relato poético hegemónico dentro del canon fijado en dura pugna entre las élites intelectuales de este país, gracias a la mayor extensión y consistencia de sus redes clientelares y sus circuitos de dones, sinecuras y propinas, sea poesía mainstream. En todo caso es poesía institucional, poesía del régimen cultural, pero nunca ha sido una poesía de masas ni hay ningún grupo editorial de relevancia interesado en 
darle este carácter. Aunque ante los últimos movimientos de aproximación de unos y otros, quién sabe en qué deparará esto; si acaso, como algo hermoso, tal vez se reconozcan, pues hacen lo mismo y al servicio de lo mismo, con la salvedad de la edad y el hábito. ${ }^{2}$

Quién sabe si conseguida la tan ansiada transformación en mercancía para consumidores ávidos de pasividad inducida, esta poesía de la vieja y la joven experiencia encontrará por fin su lugar en las grandes superficies al lado de los libros de autoayuda, horticultura y meditación, no lejos de la sección multimedia y la conexión a internet. El camino a la desactivación social está hecho de buenas vibraciones.

\section{REFLEXIONES SOBRE EL FONDO DE ARMARIO}

Aunque no llegara a profundizar en sus mecanismos, Marx descubrió cómo eran las propias condiciones objetivas de la sociedad capitalista las que provocaban la deformación cognoscitiva, dándole forma al carácter clasista del conocimiento. Así, el propio sistema segrega la opacidad de sí mismo ante la conciencia de los individuos. De ahí que toda aprensión de la realidad no es producto de una deformación gnoseológica de la conciencia del sujeto en su relación con el objeto, sino el carácter eminentemente político de toda teoría del conocimiento. De ahí la inocencia de un pensamiento que pretenda experimentar la realidad al desnudo, cuando esta solo se puede experimentar mediatizada por la ilusión de que es posible experimentar lo real, cuando lo real está entretejido por la ideología.

Tal vez el problema de base de la otra sentimentalidad fue querer alumbrar una subjetividad otra en unos poetas que no quisieron, o bien no supieron, abandonar la subjetividad burguesa que los había construido (Rodríguez, 1990), confundiendo lo que se imaginaban ser con lo que en realidad eran (Marx, 2003). Su marxismo nunca fue tal, apenas un materialismo contemplativo (pasivo, sensible) que conecta directamente con lo que Marx criticaba a Feuerbach, incapaz de ir más allá de lo contemplado, subvertir o atacar el orden de lo real dado. En efecto, como Feuerbach, captaron la realidad de modo idealista, expresaron no su relación con sus condiciones de existencia sino la manera en que vivían su relación con sus condiciones de existencia, por tanto nada más lejos de Althusser y todos más cerca de lo que Marx llamara la izquierda hegeliana. Es por ello por lo que su poesía no podía sino aspirar a constituirse como un discurso pacificador que escondía las contradicciones o bien fingía superarlas. No podían decir no a un mundo insoportable (Rodríguez, 1999:244), porque su inconsciente ideológico hacía el mundo perfectamente soportable, un mundo que, lejos de cuestionar el yo, lo producía como reflejo de lo existente.

De otro lado, su miedo a que el yo individual se disolviera en el "nosotros" o en "ellos" les abocó a la única salida posible, presentar el yo individual como una categoría abstracta capaz de abarcar la totalidad, de nuevo hegeliana, de los "normales", con lo que de paso se elude la lucha de clases y, lo que es más importante, se hace pasar por natural la dominación de la clase dominante (Althusser, 2005). Ya alertaban Marx y Engels de que esta operación encaminada a "presentar su propio interés como el interés común de todos los miembros de la

${ }^{2}$ Consulta en el siguiente enlace 
sociedad" (Marx-Engels, 2014: 59), no hace sino ocultar el fundamento de la dominación de clase (Kofman, 1975).

Cuando el adalid de la poesía de la experiencia nos dice que "Un beso es tan histórico como una comisaría o como un golpe de Estado" (García Montero, 2003:11), lo que nos está diciendo no tiene nada que ver con el marxismo, ni con el materialismo histórico, nos está situando ante una categoría abstracta (un beso) que no tendrá nada de histórico hasta que no se dé en una comisaría o en medio de un golpe de Estado. El poeta marxista lo sabe, pero el poeta ejecutivo bohemio, el relativista, en sus profundas convicciones idealistas, equipara los besos, las comisarias y los golpes de Estado; y equiparar poesía, comisarías y golpes de estado es no discriminar las distintas categorías de análisis, sus relaciones mutuas y su distinto papel en los procesos sociales. Como diría el filósofo, "los frutos de su cabeza han acabado por imponerse a su cabeza" (Engels, 2014). Todo, pues, se confunde en medio de un tufo posmoderno fruto de la mezcla de materiales diversos en la idea de conectar lo que está separado en "la noche del entendimiento donde todos los gatos son pardos" (Hegel, 2008).

Juan Carlos Rodríguez era consciente de esto y así lo manifestó al decir que La Otra sentimentalidad había nacido muerta. Desde luego, si nos atenemos a las declaraciones programáticas de la poesía de la experiencia, encontramos un difícil encaje entre los presupuestos teóricos de Juan Carlos Rodríguez y las materializaciones visibles de la corriente, toda ella preñada de un esencialismo que difícilmente puede tener encaje histórico y una práctica de una moralidad esquizofrénica que, si queda muy bien en el papel, deja mucho que desear cuando enfocamos hacia aquellos aspectos menos poéticos y más desagradables de la trastienda lírica, pero que son los que, en suma, definen la hegemonía a través del control editorial, la presión mediática, la sobreexposición pública, la crítica servil, los premios literarios amañados, el clientelismo y nepotismo en los contratos universitarios, en la concesión de becas, bolsas de viaje, cursos y congresos o la utilización espuria de cargos sindicales pues, por desgracia para ellos, la moral poética lava, pero no tanto como luego sus antagónicas prácticas ensucian.

Ni desde la poesía de la otra sentimentalidad ni desde la poesía de la experiencia se atacó a la ideología dominante, pues en todo momento se plegó a ella, de ahí también que de sus temáticas fueran excluidas la explotación y las contradicciones de clase. No hubo una respuesta al poder en tanto ente globalizado, inmoral y antisocial, categorías que, paradójicamente, se convirtieron en atributos de ambas corrientes, tanto en sus prácticas (cesarismo, nepotismo, clientelismo, corrupción, etc.) como en sus discursos (individualista, ensimismado, endogámico, capitalista). Por todo ello, esta poesía, como diría Althusser (2001), lejos de cambiar el mundo, lo apuntala y reproduce, lo naturaliza en todo su espanto, unas veces conscientemente y otras no tanto. Autopresentándose sin más como una práctica expresiva de la cotidianidad, su función es la del reconocimiento ideológico: el sujeto creador y el sujeto consumidor de arte o literatura se reconocen en la imagen especular de una subjetividad, la burguesa, supuestamente autónoma y libre (Rodríguez, 2011:7-36).

$\mathrm{Y}$ todo esto, incomprensiblemente, se sigue haciendo bajo el lejano cielo protector de las teorías de Juan Carlos Rodríguez, a quien estos poetas se niegan a leer para que no les estropee el invento; pero ante lo que él, y esto me sigue resultando aún más inexplicable, guardó un helador 
silencio, matizado con desplantes, salidas por la tangente y reflexiones reiterativas donde no dejaba de afirmar, como hacía treinta años, que el gran mérito del capitalismo es haberse diluido como vida cotidiana y poder presentarse hoy hecho carne con las personas normales, convirtiendo la vida, el pensamiento y el lenguaje en norma (Rodríguez, 2003).

Lo que propugnaba Juan Carlos Rodríguez, por tanto, era no una nueva sentimentalidad, sino una nueva moralidad anticapitalista que se dedicara, en literatura, en poesía, en la vida cotidiana, a hacer visible la invisibilidad que nos construye, "las redes y los nudos del sistema” (Rodríguez, 2016:15). Juan Carlos Rodríguez no se cansó nunca de decir que había que desechar las relaciones políticas establecidas: "si hacían daño las relaciones sociales y económicas establecidas, ¿cómo se podría decir sí a las mismas relaciones poéticas establecidas" (ibídem: 16). Pero está claro que incluso él se dejó querer, y unas veces dijo sí, y otras, si no dijo sí, quienes estaban a su alrededor lo dijeron por él; y desde luego, los poetas de la experiencia no es que dijeran que sí, es que se dedicaron activamente a profundizar en esas relaciones sociales y económicas que no por así instauradas eran menos dañinas, sino más tóxicas.

En efecto, como el mismo Juan Carlos Rodríguez reconoció muchas veces, la sílaba del no se convirtió en algo muy complicado de pronunciar (ibídem); tanto, que la historia que habría que transformar no pudo contar, desde luego, con estos poetas que dijeron sí, porque, al fin y al cabo, todos ellos eran producto de la Historia no en abstracto sino de la historia de su propia clase social y, sobre todo, eran el reflejo de los arquetipos dominantes en la sociedad de su tiempo, y estos, en los años noventa, eran sinónimos de éxito, pelotazo, clientelismo, nepotismo, arribismo...Y si por arriba, en las instituciones políticas y económicas, se dedicaban todos a recoger los frutos del capitalismo de amiguetes que estaba forjando el bipartidismo con la liberalización y privatización de los bienes públicos; por abajo, en las instituciones culturales, en la medida de lo posible, les fueron a la zaga en la rebatiña, aunque eso sí, revistiendo estos comportamientos bajo el pesado manto del compromiso político y moral hacia una sociedad que, en realidad, les quedaba allá lejos, en el espacio exterior sociopsicológico en el que, aunque ellos nunca se hubieran cruzado más que con sujetos de su misma clase, debían de vivir las personas normales, fueran lo que fueran tales entidades.

No sólo Leopoldo Alas, que abominó pronto del engendro experiencial, casi todas las voces disidentes coinciden en afirmar que para mediados de los noventa los poetas de la experiencia son un grupo con comportamientos auténticamente mafiosos, prácticamente copan los jurados de los premios importantes, los que están bien dotados y conceden prestigio, aunque, paradójicamente, esconden corrupción, prevaricación, cohecho, malversación, tráfico de influencias y casi todas las figuras del derecho penal y administrativo relacionadas con las viejas prácticas, tan españolas, del amiguismo y el clientelismo que, de la mano de los poetas de la experiencia, se extendieron por otros ámbitos culturales y profesionales constituyendo la sólida red de relaciones sociales clientelares que explican, mejor que sus poemas, el que al día de hoy siga siendo una corriente hegemónica. Poetas de fama y editores conspicuos, que están en la mente de todos sin necesidad de dar nombres, si en vez de a la poesía se hubieran dedicado al ladrillo, hoy serían multimillonarios (Viñó, 2006). Baste recordar solo la punta del iceberg que fue el escándalo del premio de poesía Ciudad de Burgos o las desvergonzadas listas de agraciados y jurados en premios como el Nacional, el Loewe, el Melilla, el Premio Alhambra de Poesía 
Americana, Premio Casa de América, Premios de Poesía del Tren o tantos y tantos otros...

En este sentido, la labor que hicieron los Addison de Wit desde su blog denunciando el nivel de podredumbre de los jurados de los premios de poesía y de los poetas que aceptaban participar en estos amaños no tiene precio. La esquizofrenia y desvergüenza de todos ellos no tiene fin cuando discursean sobre la falta de valores en nuestra sociedad y la necesidad del compromiso cívico del poeta.

\begin{abstract}
Todos saben que allí pasa lo que pasa y se cuece lo que se cuece, pero esa confabulación ilícita entre empresarios del libro y autores de novelas, ensayos o poemas apenas crea escándalo. A los corruptores se les trata de mecenas, a los corrompidos de honrados talentos, a los mamporreros de jueces justos, a los concursantes de esperanzados y al público de compradores o lectores, a los que tanto debo y tanto quiero, de agradecidos por tanta letra e historia entretenida. Es raro que alguien proteste y más raro es que la queja pase de la palabra y el fraude llegue a juzgado alguno... (...) La familia real, Urdangarin mediante, y las autoridades competentes -soberanistas centrífugos o federalistas centrípetos- homologan con su presencia la farfolla de los actos de entrega. El periodismo cultural (¿pero es posible tal oxímoron?) vende las sospechas para luego bendecir las panoplias con gusto y vocación concelebrante. Los jefes de redacción disponen alfombras rojas para entrevistas y despieces. Los premiados y premiadas son bienvenidos a todo festejo literario y sus bolos sufren un incremento exponencial en número y emolumentos. Probada su buena disposición, pasarán a formar parte de jurados y novelerías. La fama les facilitará ocupar tribunas desde las que desgarrarse la ropas y condenar la corrupción nuestra de cada día (Bértolo, 2017).
\end{abstract}

\title{
SEMBRANDO LA SEMILLA
}

A pesar de esto, desde principios de los años noventa se produjo en el campo literario español un fenómeno curioso con el surgimiento de grupos y personalidades más o menos conectadas gracias a encuentros, revistas, fanzines y pequeñas editoriales autogestionadas que abundan en la estela de la cultura alternativa de los setenta y que, en buena lógica, trataban de combatir el discurso neoliberal y su hegemonía cultural.

Muchos hablan de la poesía que hacen como un nuevo movimiento, la poesía de la conciencia crítica, en su expresión más conocida (García Teresa, 2013); pero lejos de escuelas, su apuesta siempre estuvo por aglutinar compañeros de viaje: gente real, tangible, movilizable, solidaria... Los jalones hasta llegar aquí han sido de lo más variado. Vamos a exponer algunos de ellos, al menos los que mejor nos parece que la explican.

En 1991, mientras el llamado "Nuevo Orden Mundial” empezaba a hacer de las suyas, y palabras entonces desconocidas como globalización, inmigración, guerra de Irak, crisis ecológica o cambio climático se incorporaban tímidamente al vocabulario de la disidencia, en Madrid, un pequeño grupo de amigos que participan activamente en movimientos sociales de signo antibélico y ecológista, entre otras cosas, escriben también poesía, son: Jorge Riechmann Cántico de la erosión (1987), y Fernando Beltrán El Gallo de Bagdad (1991); ambos coinciden en ese tiempo en la necesidad de escribir una poesía practicable, entrometida, no ajena a los problemas cotidianos, locales y globales..., una poesía donde el poeta compagine a Horacio con Harvey, a Quevedo con Simmel o a Garcilaso con Keynes.

En 1992, se funda la UEPV (Unión de Escritores del País Valenciano). Como en el caso anterior, el movimiento pacifista y la insumisión vuelven a ser el aglutinante de estos escritores. 
Un año después, será un grupo de afinidad surgido de la UEPV el que bajo el nombre colectivo de Alicia Bajo Cero redacte uno de los análisis más demoledores de crítica literaria que se han publicado en nuestro país: Poesía y Poder. En ese grupo visibilizamos a Enrique Falcón La marcha de 150.000.000 (1994) y Antonio Méndez Rubio El fin del mundo (1995), empeñados en la urgente necesidad de reconstruir una cultura radical. Otro miembro de la UEPV, Uberto Stabile Empire Eleison (2000) recala en esos años en Huelva, y pone en marcha allí ese empeño crítico, radical y aglutinador a través de la Asociación Cultural 1900, a la que pronto se suma la Asociación Cultural Crecida, con Eladio Orta Resistencia por estética (1999) o Edad de Hierro (1997) de quien esto escribe, y otras pequeñas asociaciones culturales que marcarán la escena alternativa onubense hasta la actualidad.

Como adelantábamos, no será hasta 1993 cuando surja el demoledor trabajo Poesía y Poder, del colectivo Alicia Bajo Cero, con una acertada y rigurosa crítica a la poesía de la experiencia. Con ellos, se inician, en los noventa, una serie de movimientos de resistencia que habían venido creciendo desde los márgenes y que marcarán algunas de las prácticas poéticas y experimentales empeñadas en hacer visibles las tragedias, los desmanes del capital, la lucha de clases, los falseamientos de la realidad y las posibilidades aún inéditas de explorar nuevas formas de relación y vinculación colectivas.

Esta nueva poesía política, comprometida, insurgente y, a la vez, alejada del viejo realismo social, pudo haber alcanzado en 1998, gracias a la edición de Feroces, antología de la poesía radical, marginal y heterodoxa, una cierta visibilidad y consistencia grupal de no haber sido por lo heterogéneo del volumen final, que se editó pensando más en lo que de espectacular podría haber en hacer público un conjunto de poetas raros, que en un libro que trajera la atención sobre la existencia de estas corrientes críticas que señalaban un punto de inflexión o, al menos, el cuestionamiento generalizado de muchos de los planteamientos de la poesía de la experiencia. Y si bien este objetivo no se consiguió, tampoco se ha podido evitar que las voces críticas sigan creciendo por los márgenes.

En 1994, Uberto Stabile le da un carácter internacional a este movimiento de agitación cultural y nacen los Edita: Encuentros Internacionales de Editores Independientes y Alternativos, una plataforma para la vinculación y el entramado de proyectos alternativos que ya va por su XXXVII ${ }^{a}$ edición y que congrega, cada año, a más de doscientos editores alternativos, desde fanzinerosos del folio doblado y la grapa a editores independientes venidos de los cinco continentes. Edita se convierte así en una cita ineludible para los defensores de una cultura y una literatura autogestionada, horizontal, vinculativa y crítica, que busca sus propios canales de expresión y difusión al margen del sistema. Allí siguen convergiendo multitud de colectivos madrileños, valencianos, vascos, catalanes, extremeños, canarios, mexicanos, argentinos, colombianos, portugueses, brasileños, etc. que en la exposición de sus prácticas han conseguido entramar una consistente red de producción, difusión y consolidación de la escena cultural alternativa internacional. Tomando como base el laboratorio experimental de Edita, será Isla Correyero quien descubra para el gran público parte de estos discursos invisibilizados y contrahegemónicos con el volumen antológico Feroces (1998) a pesar, de que, como ya dijimos más arriba, esto solo sea posible descifrarlo espigando en el totum revolutum que fue dicho volumen. 
En 1999, quien suscribe estas líneas, muy vinculado al trabajo de agitación del círculo onubense, dará forma al Encuentro Voces del Extremo, específicamente dedicado a la reflexión social en clave crítica desde la poesía, y que en sus convocatorias anuales viene aglutinando a más de 150 poetas venidos de la península e Iberoamérica. Entre Sevilla y Cádiz, ese mismo año comienza su actividad el colectivo Circo de la Palabra Itinerante, con un ciclo de poesía en resistencia que se mantendrá por espacio de un año y que ha dado después paso a un sinfin de talleres de escritura, recitales, libros, etc., que aún hoy continúan. En dicho colectivo encontramos, entre otros, a David Eloy Rodríguez (Miedo a ser escarcha). En Madrid, David Méndez y Álvaro Moreno Marquina comienzan a publicar el MLRS (Manual de Lecturas Rápidas para la Supervivencia), hoy transformado en una página web imprescindible para quienes quieran acceder a estas poéticas radicales, junto con la web ya extinta pero aún visitable de Lunas Rojas. Poco después, comienzan las actividades del Grupo Surrealista de Madrid y el colectivo de Trabajadores Culturales La Felguera, el Grupo Arbeit o la Congregación Telepoiética, de todos ellos hay abundantes materiales en internet con los que hacerse una idea de lo que han venido a significar para el desarrollo de una cultura de signo autónomo y anticapitalista.

Extendiéndose hasta la actualidad, nacen en esos años, con voluntad vindicativa y generosa, varios proyectos editoriales de signo crítico. Así, desde Alzira, la Editorial Germanía publica, dentro de su colección Hoja por Ojo, dirigida por Jorge Riechmann y José María Parreño, entre otros libros, Resistencia por estética de Eladio Orta y Cartas de amor de un comunista de Isabel Pérez Montalbán. En Ayamonte, la editorial Crecida publica Tatuajes en tinta azul de Daniel Bellón, Estado de Sitio de Antonio de Padua Díaz, o Maricón en tierra de David Pielfort. En Huelva, Uberto Stabile desde Aullido Libros publica, entre otros, La Libertad, ciudad de paso de Omar Pimienta. En Béjar, Luis Felipe Comendador inicia la andadura de LF Ediciones con libros como Berenjenas pa los pavos de Eladio Orta o ¿Todo ba bien? de Juanjo Barral. En Barcelona se publica la monumental Lizania, obras completas del poeta Jesús Lizano. En Logroño, el colectivo Cuatro de Agosto inicia un conjunto de publicaciones artesanales entre las que destaca El amor, la ira de Enrique Falcón. En Zaragoza, Nacho Escuín, desde la editorial Eclipsados da a la imprenta Insomnio en Ramala, de Ángel Petisme. En Asturias, desde el Ateneo Obrero de Gijón, David González edita, entre otros, Canciones de la gran deriva de Vicente Muñoz Álvarez o El grito del oasis de Antonio Martínez Ferrer. Mientras, en Canarias, Ernesto Suárez, desde Ediciones Idea, da a luz libros como Amonal y otros poemas de Enrique Falcón y el colectivo editorial Baile del Sol comienza su andadura con el objetivo de dar a conocer el conjunto de las escrituras críticas que se estaban desplegando desde mediados de los años noventa, ellos editarán El amor ya no es contemporáneo de David González o Habitación desnuda de Uberto Stabile, entre otros títulos de poetas fundamentales como Jorge Riechmann, Daniel Macías, Ana Pérez Cañamares, Inma Luna, Vicens Camps, etc.

Tampoco han faltado los lugares donde encontrarse: Mollina, Navajas, Chiclana, Alicante, Tenerife, Priego, Valencia, Gijón, Zaragoza o La Laguna celebran encuentros puntuales que siguen construyendo esta idea de poesía radical, crítica y en resistencia que además, en 2002, celebró en Madrid el primer Foro Social de las Artes, un espacio para la comunicación, la discusión, el análisis y las prácticas artísticas en relación con la producción de una conciencia crítica. A este primero, le seguirán otros dos, en Valencia y Madrid, con la presencia de más de cuarenta 
organizaciones sociales y culturales, que desplegarán sus acciones sobre el espacio en la idea de animar la articulación de la creatividad social en las periferias urbanas. En Sevilla, el Circo de la Palabra Itinerante organiza, superando el boicot institucional y policial, la Contracumbre Poética a la Cumbre de Jefes de Estado, con una participación de más de treinta poetas críticos. En Baracaldo, los talleres de escritura colectiva de La Galleta del Norte (Josu Montero, entre otros), cumplen veinte años entramados con el tejido asociativo de los barrios. Poco después lo hará el programa de radio La poesía es un arma cargada de futuro, dirigido por el poeta José Montoro en la radio libertaria Radio Klara. Se crea la Plataforma de Escritores contra la Guerra. Ángel Petisme se traslada a Bagdad junto con la Plataforma de Mujeres Artistas, en una acción solidaria para parar la guerra; de esta experiencia surge el libro El cielo de Bagdad.

Desde 2003, David Franco Monthiel, desde la web Rebelión, Enrique Falcón desde el periódico anarcosindicalista Rojo y Negro, Alberto García Teresa desde Diagonal, el autor de estas páginas desde CNT o el Grupo Surrealista de Madrid desde Salamandra continúan abriendo nuevos espacios para las prácticas poéticas en resistencia, ampliados ahora gracias a los blogs de David González (Los que viven conmigo), Uberto Stabile (Los días contados), Daniel Bellón (Islas en la red), Luis Felipe Comendador (Diario de un Savonarola), Daniel Macías (La tierra de la piedra negra), Conrado Santamaría (Escombros con hoguera), Eladio Méndez (Veturia), el colectivo Voces del Extremo, etc.

Entre 2004 y 2016 salen a la luz, entre otros muchos, los luminosos libros de Vicent Camps, Taller, Eladio Orta, Ridiculum vitae / Antisonetos, Cristina Morano, Cambio climático, Pedro L. Verdejo, Crisis sistémica, Patricio Rascón, Parte de paz/ Olvidar el olvido, Antonio Martínez i Ferrer, Corre, corre niño de arena, Pura López Cortés, Alacena, Antonio Crespo Massieu, Elegía en Port Bou, Rafael Calero Palma, Versos de alambre de espino, Mada Alderete Vincent, La casa de la llave, Begoña Abad, Begoña en ciernes / La medida de mi madre, Bernardo Santos, Global y roto / Con el paso cambiado, David Eloy Rodríguez, Desordenes, José María García Linares, Muros, Jorge Maíz Chacón, Hirsutos y maleantes, Miguel Ángel García Argüez, Danza caníbal, Antonio Méndez Rubio, Por más señas, José María Gómez Valero, Travesía encendida, David Franco Monthiel, Las cenizas de Salvochea / Libro de las servidumbres, Enrique Falcón, Porción del enemigo, Inma Luna, No estoy limpia, Juako Escaso, Mañana sin amo, Enrique Falcón, Amonal, Isabel Pérez Montalbán, Un cadáver lleno de mundo, Jorge Riechmann, Conversaciones entre alquimistas, Daniel Bellón, Lengua de signos, Ángel Petisme, Insomnio de Ramalah, Eugenio Castro, Mal de confin, Juan Carlos Mestre, La bicicleta del panadero, Ángel Calle, Los vinculos / Utopistas y desutópatas, Patricia Olascoaga, Vayamos al grano, Antonio Rigo, Dias de radio y niebla, David Pielfort, La isla de Camarón, Eva Vaz, Metástasis, Ángel Guinda, Rigor Vitae, Matías Escalera Cordero, Grito y Realidad, María Ángeles Maeso, Basura Mundi, Ana Pérez Cañamares, Economia de guerra, Daniel Macías, Neuroguerilla / Como nieve en Sevilla o sobre la depresión del diez. I Niño Edén/ Guadalquivirmente o los mil yogas del flipar, o Esperar Sentado, El amor en los tiempos del despido libre, o Salirse de la fila, de quien firma este trabajo; los ensayos Los días en Rojo del Grupo Surrealista de Madrid, Resistencia de materiales, de Jorge Riechmann, Las prácticas literarias del conflicto (registro de incidencias: 1991-2010) de Enrique Falcón, Poesía de la conciencia crítica (1987-2011) de Alberto García-Teresa y La voz común: una poética para reocupar la vida, de quien rubrica este trabajo, además de las antologías colectivistas Prosas Presas, un libro colectivo escrito por las mujeres encarceladas en la prisión de Can Brians, 11-M: Poemas contra el olvido, Poemas para cruzar el desierto o 
la esencial Disidentes (antología de poetas críticos españoles (1990-2014) de Alberto García-Teresa, y nuevas editoriales como Calumnia, La Oveja Roja, Ruleta Rusa, Lupercalia, El Desvelo, Enclave Libros, La Linterna Sorda, Babilonia, Amargord o Piedra, Papel, Tijera, amplían el catálogo de textos críticos.

Finalmente, los encuentros autogestionados de Voces del Extremo se extienden por toda la geografía, celebrándose en Béjar, Logroño, Madrid, Valle del Jerte, Tenerife, Valencia o Bilbao, agrupando creadores en torno a este proyecto colectivista, recuperando espacios urbanos e insuflándoles vida, información y comunión, cargando de dimensión política la comunicación en la medida que la poesía y el arte se hacen políticos cuando se funden en prácticas colectivas que movilizan los cuerpos y las emociones, abandonando el viejo paradigma de lo político como una cuestión de mensaje, liberando lo político para el cambio y despertar de los cuerpos y las conciencias capaz de transformar la vida.

Unos pocos jalones, ya lo dijimos, pero detrás de cada uno de ellos, de cada texto, de cada proyecto, de cada encuentro, lo que está anidado no es conseguir la publicación de un nuevo libro, lo que anida, lo que crece con todas esas prácticas, más allá de visibilizar una estética, es producir una ética, es decir, afirmar que somos la forma en la que nos organizamos y el modo en el que nos relacionamos. El libro es la excusa perfecta para lo que estos poetas pretenden y que es, ni más ni menos, revelar el mundo por medio de la palabra; su empeño no podría ser más hermoso, lástima que el mundo también esté hecho de palabras y, lo que es peor, que esté hecho con palabras de las que no somos dueños.

Por ahí sigue la lucha, porque la poesía de la conciencia crítica más que establecer un canon, ejercer la hegemonía de un discurso, imponerse totalitariamente o transformarse en un objeto de consumo, ha pretendido problematizar la vida, criticar, combatir y hasta intentar desmontar el orden existente, superar toda dualidad entre lo público y lo privado, dar rienda suelta a las estrategias materialistas y a las fantasías más visionarias, a lo espiritual y a lo material, a la línea clara y la poesía oscura, el objetivismo documental y la deriva libertaria, el torrencialismo irracional y el vitalismo distanciado, el vanguardismo y el realismo. Porque todo ello no son sino facetas de la misma rebeldía cuando se asume lo fundamental, el que nos hemos transformado en tanto poetas en un depósito de bienes de uso, de saberes, de herramientas y materiales constructivos, de moralidad que extiende, en suma, unas prácticas libertarias que siguen siendo el cemento con el que nos constituimos como un grupo de afinidad, como colectivo, como comunidad humana, para poner en común habilidades sociales y problemas colectivos que nos atañen como ciudadanos y como trabajadores culturales, contactarnos y movilizarnos para una acción que, desde la palabra, pretende interrumpir el discurso de la ideología dominante sí, pero, sobre todo, que desde sus prácticas pretende educarnos para la libertad, para transformarnos en libertarios. Porque nuestras propuestas no pretenden tomar el poder, sino mostrar las posibilidades de vivir de forma diferente, creando espacios de cooperación, ayuda mutua, trabajo y resistencia comunitaria, colectivos que nos permitan gozar no de una nueva poesía de la experiencia sino de la experiencia de la poesía, que no es más que la experiencia de participar intensamente en un proyecto vital que no por ser colectivo es menos personal, menos físico o menos espiritual, un proyecto que nos expone a todos y a cada uno ante las grandes preguntas que hay que resolver de manera urgente ante el colapso civilizatorio que se avecina, a la necesidad 
de estar juntos, de compartirnos, de regalarnos, de cuidarnos, de vivir mejor con menos, más frugalmente, en paz con la naturaleza y con los seres sintientes, estableciendo una economía autosuficiente, de escala humana y dimensiones locales, que haya puesto fin al trabajo alienado y a la mercantilización de la existencia, regida en lo político por la asamblea, la democracia directa, la igualdad de género, el desarrollo de la atención y los cuidados.

$\mathrm{Y}$ nuestro mayor logro es saber que todo esto comienza a abrirse paso, de forma fragmentaria, imperfecta e intermitente, y desde luego, en un contexto político, económico y mediático tremendamente hostil, que hace aún más hermosa nuestra empresa de crear y extender los espacios temporales, difusos o permanentes, donde vivir la utopía de los pies negros, de los pequeños, de los precarios, de los desvergonzados, de los hijos de mala madre, de los que quieren ver, de los que se atreven a denunciar las desnudeces del Imperio y no le temen a la verdad.

Por esto todo el mundo ocultaba el que creía que era su secreto. Hasta que un negro, palafrenero del rey, que no tenía honra que conservar, se acercó y le dijo:

-Señor, a mí lo mismo me da que me tengáis por hijo del padre que creí ser tal o por hijo de otro; por eso os digo que yo soy ciego o vos vais desnudo.

El rey empezó a insultarle, diciéndole que por ser hijo de mala madre no veía la tela. Cuando lo dijo el negro, otro que lo oyó se atrevió a repetirlo, y así lo fueron diciendo, hasta que el rey y todos los demás perdieron el miedo a la verdad y entendieron la burla que les habían hecho.

Don Juan Manuel. El conde Lucanor 


\section{BIBLIOGRAFÍA}

ABRIL, J.C. (2016). "Velocidad y lentitud en poesía española contemporánea". SÁNCHEZ, Remedios (coord.). Palabra heredada en el tiempo. Tendencias y estéticas en la poesía española contemporánea (1980-2015). Madrid: Ed. Akal: 359-368.

Althusser, L. (2001). Écrits philosophiques et politiques II. Paris: Le Livre de Poche.

Althusser, L. (2005). Ideología y aparatos ideológicos del Estado. Nueva Visión: Argentina.

Bellveser, R. (2016). "Por una recuperación del espíritu del Salón de los Independientes (Homenaje a Gregorio Morales)" SÁnCHEZ, Remedios (coord.). Palabra heredada en el tiempo. Tendencias y estéticas en la poesía española contemporánea (1980-2015). Madrid: Ed. Akal: 149-165.

BÉRTOLO, C. (2017). “Cloacas y premios literarios”

Cienfuegos, A. (2013). "Poesía y corrupción. Un ensayo testimonial de las mafias literarias en México e Iberoamérica". Otro Lunes. Revista hispanoamericana de cultural 30. Diciembre (2013).

García Montero, L. (2003). "Poetas políticos y ejecutivos bohemios". Mariscal, José M., PARDO, Carlos (eds.). Hace falta estar ciego (Poéticas del compromiso para el siglo XXI). Madrid: Visor: 11-23.

GonZÁlez, A. (2003). "Sobre la poesía, un alegato”, MARIsCal, José M., PARdo, Carlos (eds.). Hace falta estar ciego (Poéticas del compromiso para el siglo XXI). Madrid: Visor: 63.

GranAdOS, A. (2011). "Reivindicando a Javier Egea".

HEGEL, G. W. (2008). Fenomenología del espiritu. Madrid: FCE.

Kofman, S. (1975). Cámara oscura de la ideología. Madrid: Ediciones JB.

MARX, K. (2003). El dieciocho Brumario de Luis Bonaparte. Madrid: Alianza Editorial.

MARX, K, ENGELS, F. (2014). La ideología alemana. Madrid: Akal.

Rodríguez, J. C. (1990). Teoría e historia de la producción ideológica. Madrid: Akal.

RodríGueZ, J. C. (1999). Dichos y escritos. Madrid: Hiperión.

Rodríguez, J. C. (2003). "La poesía política de Alberti”, MARiscal, José M., PARdo, Carlos (eds.). Hace falta estar ciego (Poéticas del compromiso para el siglo XXI). Madrid: Visor.

RodríGuez, J. C. (2011). Tras la muerte del aura (a favor y en contra de la ilustración). Granada: Editorial Universitaria de Granada.

Rodríguez, J. C. (2016). "La poesía del NO (notas para una aproximación a "la otra sentimentalidad" y a la poética de la experiencia)", SÁNCHEZ, Remedios (coord.). Palabra beredada en el tiempo. Tendencias y estéticas en la poesía española contemporánea (1980-2015). Madrid: Ed. Akal: 9-25.

VIÑó, M. (2006). EL PAÍS: la cultura como negocio. Nafarroa: Txalaparta. 